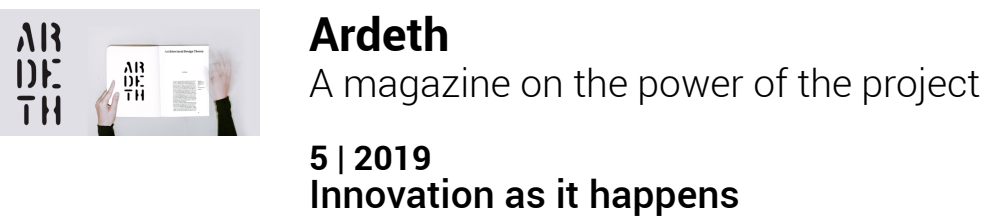

\title{
Principles of Construction. An Ontology of Design
}

\section{Enrico Terrone}

\section{(2) OpenEdition \\ Journals}

Electronic version

URL: http://journals.openedition.org/ardeth/313

ISSN: 2611-934X

Publisher

Rosenberg \& Sellier

Printed version

Date of publication: 1 November 2019

Number of pages: 26-41

ISSN: 2532-6457

\section{Electronic reference}

Enrico Terrone, «Principles of Construction. An Ontology of Design », Ardeth [Online], 5 | 2019, Online since 01 May 2020, connection on 21 November 2020. URL : http://journals.openedition.org/ardeth/ 313 


\section{Principles of Construction. An Ontology of Design}

Enrico Terrone

Abstract

If ontology is the study of being, the ontology of design studies the specific being of design. I propose an ontology of design that rests on the distinction between design as an activity and the design as the outcomes of this activity. I begin with arguing that a design is a principle of construction of artifacts that belongs to the ontological category of norms. Then, I exploit this account of the designs as norms to build up an account of design as normative practice. Just as politics governs the life of people, design governs the life of artifacts. Lastly, I show that the ontological conception that I have proposed can shed some light on three important aspects of design, namely, its forms (architecture versus engineering), its processes (individual versus collective), and its values (innovative versus traditional).

Affiliation

Universitat de Barcelona, Departament de Filosofia

Contacts: enrico [dot] terrone [at] ub [dot] edu

Received:

06 August 2019

Accepted:

28 October 2019

DOI:

10.17454/ARDETH05.03

ARDETH\#05 


\section{The English term "design" can be used both as an uncountable noun and as a countable one.}

This paper proposes an account of design as broad as possible, which aims to remain neutral on three distinction. First, the distinction between engineering design and architecture design. Second, that between design as an individual act of creation and design as a collective process. Third, that between innovative and traditional design. The fact the my account aims to remain neutral on these issues does not mean that I do not care about them. Quite the opposite. The point is that, in order to properly address these issues, we need an account of design that is independent of them. An account that is ontological in the sense that it concerns the being of design independently of our preferences as regards its forms (architecture versus engineering), its processes (individual versus collective) or its values (innovative versus traditional). As Achille Varzi (2011: 407) aptly points out, "According to a certain, familiar way of dividing up the business of philosophy, made popular by Quine, ontology is concerned with the question of what entities exist (a task that is often identified with that of drafting a "complete inventory" of the universe) whereas metaphysics seeks to explain, of those entities, what they are (i.e., to specify the "ultimate nature" of the items included in the inventor)". In this paper I shall develop an ontology of design in the sense that I shall try to find the place of design in the "inventory" of the universe. Moreover, I will sketch a metaphysics of design in the sense that I will also try to figure out what design is (though without any claim to reach what Varzi calls the "ultimate nature").

That being the case, it is worth noting that the English term "design" can be used both as an uncountable noun and as a countable one. As uncountable, "design” designates the human activity of creating artifacts whereas, as countable, it concerns the production of a certain artifact. These two meanings are deeply intertwined and yet distinct. The strategy of this paper consists in focusing on the countable meaning with the aim of shedding some light on the uncountable one. Thus, I shall propose a unified ontological account of what a design is, thereby exploiting it in order to figure out what design is as a human activity, and how this is related to its forms, its processes and its values. 


\section{The Concrete and the Abstract}

At a basic ontological level, we can distinguish between concrete entities, which have a place in space, and abstract entities, which lack a place in space (cf. Lowe, 1998). I conceive of a design as an abstract entity that governs the construction of concrete entities, which I call its instances. A design is a principle of construction of its instances, that is, a norm that specifies how to construct its instances.

Norms do not have a place in space. Although there can be places in space for some inscriptions that record a norm, the existence of the norm does not depend on the existence on a particular inscription of it; the inscription can disappear while the norm keeps existing. A norm can exist even in the absence of any inscription, provided that the norm is supported by the appropriate mental states (e.g. beliefs, intentions, expectations) of the members of a social group (cf. Lewis, 1969; Gilbert, 1989; Searle, 1995; Bicchieri, 2006). Thus, a design, as a norm, lacks a place in space even though it can be recorded by inscriptions that have a place in space, and instantiated by concrete entities that also have a place in space.

In everyday life, we are mainly interested in the concrete instance of a design rather than in the design itself as an an abstract entity. If I have to do the laundry, I need a particular washing machine. I do not care about the abstract design of a washing machine, that is, a principle of construction of washing machines. I need that this principle has been applied; I need an instance of it, a particular washing machine. However, if we take a broader perspective, we can understand why designs as abstract entities also matter. When, for example, engineers design a new washing machine, their main focus of attention is the abstract entity, not the concrete one. Engineering design creates an abstract entity that can then be instantiated by a multiplicity of concrete entities. In the case of architecture, it is debatable whether a design can be instantiated by a multiplicity of concrete buildings or is rather essentially associated to one building (cf. Lopes, 2007; Armando, Durbiano, 2017; Terrone, 2018a). Nevertheless, the design remains distinct from the building whose construction it governs. The latter has a place in space that the former, as a norm, lacks. From this perspective, designs can be compared to

\section{Norms do not have a place in space.}




\section{An organic species surely ceases to exist when its last specimen disappears, while a design can exist even if there are no concrete instances of it.}

biological species, inasmuch as both are abstract entities that have concrete individuals as their instances, namely, artifacts for designs and organisms for species. However, in the philosophy of biology, there is an alternative ontological approach according to which species are concrete individuals scattered in space, as it were, of which organisms are components (see Ghiselin, 1974; Hull, 1976). One might apply this approach to artificial individuals, thereby conceiving of a design as the particular individual who has the various concrete designed artifacts as its components. Nevertheless, the conception of a design as an abstract entity is closer to the way people usually think about designed artifacts, and therefore more suited to an ontological account of such entities, whose existence, unlike that of organisms, depends on the thoughts of the people who create and use them. For an engineer who designs it or for a driver who drives it, a particular helicopter is not a component of a concrete entity "scattered" in space; it is an entity in its own right, that instantiates a principle of construction, namely the design of that helicopter. Moreover, an organic species surely ceases to exist when its last specimen disappears, while a design can exist even if there are no concrete instances of it, and thus it is better conceived of as something essentially different from the totality of its particular instances.

\section{Prototypes and archetypes}

A design can be created either implicitly, through the construction of a concrete particular (the "prototype" or "model"), or explicitly, through the creation of a principle of construction of particulars (the "archetype” or "project”). In the latter case the design corresponds to the archetype, while in the former case it is identified by the features of the prototype that can be imitated and therefore used as a principle of construction of other particulars. Crawford Elder (2004) speaks of a "copying process" according to which artifacts would replicate in a similar way to genes and organisms.

The passage from handcraft to industrial production involves a regimentation of design as principle of construction of instances. In handicraft production the instances of a design are constructed by a craftsman who imitated a prototype, so that the instances could 
vary significantly depending on the contingencies in which imitation occurred. In industrial production, instead, the instances are constructed by a machine that conforms to an archetype by relentlessly repeating the same series of operations. In this way, the influence of contingencies is reduced to the minimum so that the instances of the same design tend to be indistinguishable one from the other.

As a norm that specifies how concrete instances should be, a design allows people to avoid wasting time and energies. One does not need to reinvent the helicopter from scratch any time one wants to make a particular helicopter. One just has to consider its design, which provides one with the fundamental indications for making a particular helicopter. In this sense, designs incorporate the intentions by which designers has established the functions of artifacts and specified them through structures (by 'structure', here, I just mean a purposeful connection of elements). As a principle of construction, a design makes it possible to construct a potentially unlimited number of instances. This is how technical reproducibility becomes possible: since the helicopter has been designed, we have a principle of construction at our disposal that allows us to produce as many helicopters as we want (provided, of course, that we have the skills and the means to build them).

Although the notion of technical reproducibility is inherent in the notion of a design (understood as the principle of construction of a multiplicity of instances), it is only with the rise of machines that an almost perfect reproduction becomes possible. This progress can be positively evaluated as it allows many people to enjoy the same artifact, but also negatively assessed because it deprives an artifact of its qualitative individuality that makes it somehow similar to a person. Such clash of evaluations underlies Walter Benjamin's famous essay The work of art in the age of its technological reproducibility (1936).

Benjamin's notion of technical reproducibility can be clarified by relying on two distinctions introduced by Nelson Goodman (1968): that between one-stage and two-stage works, and that between autographic and allographic works. While one-stage work are directly accomplished by their makers, two-stage works involve a phase of design which is distinct from the

\section{As a norm that specifies how concrete instances should be, a design allows people to avoid wasting time and energies.}




\section{The function of a particular artifact comes from its being technically reproducible.}

phase of production thereby making room for the production of a plurality of instances. If the design is nothing but the production of a material blueprint (as for instance in cast sculpture), then two-stage works remain autographic just as one-stage works are. Yet, if the design can be formally represented through a notation, then the two-stage work become allographic: it is individuated by an abstract design which allows it to generate a plurality of perfectly identical instances. While the transition from one-stage to two-stages works establishes technical reproducibility, the transition from autography to allography brings technical reproducibility to its full deployment (cf. Terrone, 2018b).

According to Beth Preston (1998), the function of a particular artifact comes from its being technically reproducible. Peter Kroes (2012) criticizes Preston's claim arguing that technical reproducibility is only a very frequent feature in the domain of artifacts, but in principle there may be purely singular artifacts, for example "one-of-a-kind technical artefacts or systems like the Oosterschelde-dam, a major accomplishment of civil engineering protecting part of the Netherlands from flooding by the sea, or the Hubble telescope and similar unique scientific instruments” (Kroes, 2012: 73). Even in these cases, however, artifacts remain, in principle, reproducible. It is only because of a geographic contingency (in the case of the dam) or economic (in the case of the telescope) that we have just one instance, those designs do not exclude the possibility of other instances if the appropriate conditions become available.

\section{The particular and the universal}

So far I have characterized design by relying on the distinction between the abstract and the concrete. Specifically, I have conceived of a design as an abstract entity that counts as a principle of construction of its concrete instances. Still, there is another ontological distinction that is relevant to design, that between the universal and the particular. As Jonathan Lowe (1998) points out, the latter distinction apparently matches that between the concrete and the abstract, but they are based on different criteria. A universal entity differs from a particular one in virtue of having instances, while an abstract entity differs from a con- 
crete one in virtue of lacking a precise location. The universal/particular divide and the abstract/concrete divide are logically connected in the sense that a concrete individual can only be a particular. In virtue of having one localization, a concrete individual can only be in that place, and therefore cannot have instances (through which, at a certain moment, it would also be in other places). For example, in virtue of being at a specific place, the Colosseum cannot simultaneously be in another place. So its being concrete entails its being particular.

On the other hand, in virtue of lacking a precise location, an abstract individual could in principle have several instances in various places. If it actually has them, it is universal. For example, the abstract individual circumference is also a universal whose instances are the particular circumferences that can be drawn in different places. However, there may be an abstract individual whose nature prevents the existence of its instances, and this would count as an abstract particular. According to Lowe (1998), mathematical sets are individuals of this kind. For example, the set $\{1,4,9\}$ is an abstract individual because it lacks a location; yet it is not a universal, because it cannot have instances.

In most cases relevant to design, the universal/particular divide and the abstract/concrete divide go hand in hand. But there is at least one interesting sort of designed abstract particulars: programming languages. The $C$ language, for example, is abstract because it lacks a location, but it is also particular because it cannot have instances. At most there are variants of the language, or its compilers and development environments, or manuals that explain how to use it. Yet, there is no particular instance of the language that entirely realize it at a certain place. Indeed, a language is not something that can have instances, and this seems to hold true also regarding natural languages such as Italian, English or French. The difference between natural languages and artificial language is not at the ontological level but rather at the empirical one. Italian, English or French are not created from scratch but rather emerge from a network of social interactions. While Dennis Ritchie created the C programming language in 1972, a natural language like Italian surely lacks parents and date of birth. Nevertheless,

\section{A language is not something that can have instances.}




\section{One might wonder whether designs are to be considered abstract or rather quasi- abstract.}

both $\mathrm{C}$ and Italian can be conceived of as abstract designs that are also particular artifacts. Specifically, C language is a principle of construction of computer programs while Italian language is a principle of construction of speech acts.

\section{The quasi-abstract}

In the domain of abstract entities, we can introduce a further distinction depending on how the notion of location is interpreted. A totally abstract individual - or abstract tout-court - has neither spatial nor temporal location; it is completely outside of space and time whereas a partially abstract - or quasi-abstract - individual has no location in space but it has at least a location in time. That is to say that there is not a place where this individual is, but there is a moment at which it begins to exist, as well as a "line of descent" along which its existence unfolds, and possibly a moment at which it stops to exist.

The circumference is a case of a totally abstract individual (unless one endorses a "constructionist" conception according to which geometric objects are the creations of mathematicians who first study them). Instead, Beethoven's Fifth Symphony is a quasi-abstract individual: it lacks a spatial location (there is not a single place to go to visit him), but it has a temporal location, starting with his creation, by Beethoven, in 1808 , and continues its existence in time until today (provided that one endorses a "creationist" accounts of works of music, as not only the supporters of anti-Platonism but also those of "Complex Platonism" do, cf. Kania, 2017).

One might wonder whether designs are to be considered abstract or rather quasi-abstract. It is tempting to treat them as quasi-abstract individuals since they are the outcome of human creativity, and thus begin to exist only when some human activity occurs. In this perspective, the design of a knife begins to exist when, for the first time in history, a human being builds a knife. However, it is not clear whether this original moment constitutes an invention, that is, bringing something into existence, or rather a discovery, that is, selecting something that already had its own reality but was not accessible. Surely the particular concrete knife is invented by our "proto-cutler", not discovered. But the corresponding design, as a principle of 
construction, could be regarded as something that the proto-cutler has, so to speak, selected in an abstract space of possibilities, just as the protogeometer would select the triangle or the circumference.

The decisive test to establish whether an individual is abstract or quasi-abstract consists in imagining of a concrete particular that it would be tempting to treat as one of its instances, but which is not on its line of descent. For example, let us imagine to travel to another galaxy and meet aliens that make things that are similar to our knives, and use them just as we use them. Would we be willing to consider these objects and our knives as instances of the same design? If the answer is affirmative, it means that the design is abstract, not quasi-abstract, because it may have instances that lie outside its alleged line of descent. The alien proto-cutler discovered the design of the artificial knife just as, in a completely different context, the human proto-cutler did so, but these discoveries do not bear upon the ontological nature of what has been discovered.

On the other hand, if we conceive of the design as a quasi-abstract individual, we should conclude that the alleged knives in the other galaxy are not instances of the same design as ours, but instances of another design, which has its own lineage that begins with its invention by the alien proto-cutler and is therefore quite distinct from ours. While the discovery does not affect the nature of what is discovered, the invention determines the nature of what is invented. Since there are two inventions, the human and the alien, there are also two designs. From this perspective, one might go up to argue that all designs are what they are in virtue of belonging to one line of descent, a "tree of technology" that would be the artificial equivalent of "the tree of life" in biology. As life evolves from bacteria and protists to plants and animals, so technology evolves from primordial inventions such as fire and the wheel to computers and drones.

\section{Creation, structure, function}

A design is created by configuring a structure in order to carry out a function. Thus, in order to establish whether a certain design is better cast as abstract or as quasi-abstract, we should consider its three fundamental dimensions, namely, creation, structure, and function.

\section{While the discovery does not affect the nature of what is discovered, the invention determines the nature of what is invented.}




\section{The line of descent does not affect the identification of an instance of the design, which thus is an abstract individual, not a quasi-abstract one.}

I call $f$-design a design identified exclusively by its function: what makes something an instance of that design is simply the ability to perform a certain function. I call s-design a design identified not only by its function but also by its structure: what makes something an instance of that design is the ability to perform a certain function in virtue of the possession of a certain structure. Finally I call c-design a design identified not only by its function and its structure but also by its creation: what makes something an instance of a c-design is not only the ability to perform a certain function in virtue of possession of a certain structure, but also having a place in a line of descent originated by the invention of that design. For example, the camera, as f-design, is individuated by the function of recording the distribution of light that can be found in a certain environment from a certain point of view. This f-design is instantiated by both the digital machines that are used nowadays and the analog machines that were used in the previous century. From this perspective, the design is an abstract individual. If we discovered that the aliens have a device of their own to record the light, we should treat that as a instance of the design since it performs the same function as our cameras. That is to say that the line of descent does not affect the identification of an instance of the design, which thus is an abstract individual, not a quasi-abstract one.

However, a more fine-grained identification can be made by taking into account the structure, i.e. by considering the s-design. This allows us, for example, to distinguish between the analog camera, which performs its function in virtue of a structure that includes the film, and the digital camera, which performs the same function in virtue of a structure that includes a matrix of photoelectric sensors. Thus, we have at least two s-designs (analog camera, digital camera) that correspond to one f-design (camera). I say "at least" because in principle each type of camera (both analog and digital) could individuate a s-design, in virtue of having a peculiar structure that fulfills its function. When the structure is considered in a way that includes even the smallest details, one may be inclined to consider a further feature of the design: its relation to the particular creative process that made it. This leads us to the c-design, which is identified not only 
by function and structure, but also by creation. In Brian Epstein's (2015) terms, a c-design is not only "anchored" to the circumstances of its creation, but also "grounded" in such circumstances, which do not limit themselves to putting in place the conditions for its existence (this is what "anchoring” means), but also make it the entity it is (that is what "grounding” means).

For example, the Leicaflex identifies a $35 \mathrm{~mm}$ single-lens reflex analog camera designed in 1964 by the engineers of the Leitz factory. In order to count as an instance of the Leicaflex, it is not sufficient that a particular possesses a certain structure and performs a certain function. It is also necessary that the production of this particular is correctly situated on the lineage originated from the creation of that type. If we found out that aliens who have never come into contact with our civilization have a camera that is indistinguishable from a Leicaflex (not only in terms of function but also in terms of structure), we would certainly be much surprised, but we could not to consider such an object an instance of the Leicaflex c-design, because its lineage is completely detached from that of the Leicaflex. As a c-design, Leicaflex is thus a quasi-abstract universal individual: before 1964, the year in which it was designed, not only there were no instances of it but they could not have been there either, because to be an instance of a c-design it is necessary to have a place on the line of descent that originates with its creation.

A c-design has not only a function and a structure, but also a history, which involves a date of birth, in which it is established as a principle of construction of its instances, and possibly a date of death - or, if you prefer, of extinction - when for some reason the construction of instances is no longer possible (for example because the information necessary to produce them is lost). In this sense, a c-design can be considered a "historical individual" whose existence unfolds over time (cf. Rohrbaugh, 2003). This makes a c-design similar to particular individuals like us, even though it differs from us in virtue of being abstract and possibly having instances. A linguistic symptom of this peculiar individuality of c-designs is the use of proper names to designate them. For example, in ordinary language 'camera' is a common name, but
A c-design can be considered a "historical individual" whose existence unfolds over time. 
By patenting an invention, the inventor establishes, as it were, the birth certificate of a certain design, binding it inextricably to the historical context in which it was created.
Leicaflex is a proper name, as the use of uppercase at the beginning of the word indicates.

The individuality of c-designs finds its juridical correspondence in the institution of patents, which plays for designs a role similar to that which the registry plays for people (cf. Koepsell, 2003). By patenting an invention, the inventor establishes, as it were, the birth certificate of a certain design, binding it inextricably to the historical context in which it was created. From then on, only those particular artifacts that their makers will appropriately place on the lineage originated by the patent (by paying the due to the inventor) could be considered instances of that design.

Design: Its forms, its processes, its values

The nature of a design in our technical culture is ultimately captured by the notion of c-design, which casts the principle of construction as a quasi-abstract entity individuated not only by its function and its structure but also by its historical origin. That being the case, if a design is a historically established principle of construction of particular artifacts, what is design as a human activity? A straightforward answer casts design as the activity aimed at producing principles of construction. In this sense, design is a normative activity just like politics. While rulers produce laws that govern the life of people, designers produce norms that govern the life of artifacts. The nature of design, which I have argued to be both normative and historical, affects its forms, its processes and its values, as I am going to show.

As regards forms of design, a basic distinction is that between architecture and engineering. Architects typically design buildings that have an essential relation to the particular place in which are located whereas engineers typically design machines that can function regardless of the particular place in which are located. This seems to suggest that architecture design is somehow less abstract than engineering design since being abstract means lacking a particular place in space. Yet, the fact that a building has a distinctive place in space does not mean that the design of that building in turn has a particular place in space. A design, as argued in this paper, is a principle of construction, a norm, and norms lack a particular place in space even when they specify how to con- 
struct something that has a distinctive place in space. In this sense, architecture design and engineering design share a basic ontological structure in spite of the ontological differences between the buildings that are produced by the former and the machines that are produced by the latter.

As regards processes of designing, individual creation and collective creation can both originate principles of construction. Although one surely can conceive a design on one's own, a design can also be the outcome of a complex social interactions. Arguably the latter option is much more common in our age in which technology is so complex that it is hard for one person to carry out a design on one's own, and yet the notion of design, as such, does not rule out this possibility.

However, there is a sense in which design is collective even when the principle of construction is entirely conceived by one person. As Wittgenstein argued with tremendous force in his Philosophical Investigations, there cannot be a private norm. Norms, as such, depend on the collective dimension of a community. Although one can conceive a norm on one's own, for the norm to be enforced a community is required, otherwise the norm would lack its essential capacity to constrain behavior. Since a design is a kind of norm, there cannot be private design. The difference between individual design and collective design is not that the former does not require a community. Rather, the difference is that the former requires a community only for the enforcement of the norm whereas the latter requires a community also for the conception of the norm.

As regards values, one might wonder what distinguishes innovative design from traditional one. The notion of creativity can be helpful for this purpose. According to a conception that is quite widespread in contemporary philosophy of mind and cognitive science, creativity is a combination of originality and relevance (cf. Boden 1994). Originality warrants that something new is created, but this is not enough for creativity since there can be new things whose production is not creative at all. For instance, I can create this word "weehdzoddvxdovdvfvbò" which surely is new and yet I've not been especially creative in doing so. What warrants the upgrade from mere originality to creativity is relevance, that is, the capacity of pro-

\section{Originality warrants that something new is created, but this is not enough for creativity since there can be new things whose production is not creative at all.}


ducing something that contributes to some purpose. This finally provide us with another important sense in which design is an essentially collective practice even when the designer designs on its own. What bestows creativity on a designed artifact, thereby enabling us to speak of innovative design, is not only the originality of the designer's ideas and intentions but also the relevance of the designed artifact to the purposes of the life of a community.

\section{References}

Armando, A., Durbiano, G. (2017), Teoria del progetto architettonico, Roma, Carocci.

Benjamin, W. (1936), The Work of Art in the Age of its Technological Reproducibility, English translation in The Work of Art in the Age of its Technological Reproducibility and Other Writings on Media, Cambridge (MA), Harvard University Press, 2008.

Bicchieri, C. (2006), The Grammar of Society: The Nature and Dynamics of Social Norms, New York, Cambridge University Press.

Boden, M. (ed.) (1994), Dimensions of Creativity, Cambridge (MA), The MIT Press

Elder, C. (2004), Real Natures and Familiar Objects, Cambridge (MA), The MIT Press.

Epstein, B. (2015), The Ant Trap: Rebuilding the Foundations of the Social Sciences, Oxford, Oxford University Press.

Ghiselin, M. T. (1974), A radical solution to the species problem, “Systematic Zoology”, n. 23, pp. 536-554.

Gilbert, M. (1989), On Social Facts, London, Routledge.

Hull, D. L. (1976), Are species really individuals?, "Systematic Zoology”, n. 25, pp. 174-191.

Kania, A. (2017), The Philosophy of Music, The Stanford Encyclopedia of Philosophy (Fall 2017 Edition), E. N. Zalta (ed.) [Available at: https://plato.stanford.edu/archives/fall2017/ entries/music/].

Koepsell, D. R. (2003), The Ontology of Cyberspace: Philosophy, Law, and the Future of Intellectual Property, Chicago, Open Court Publishing.

Kroes, P. (2012), Technical Artefacts: Creations of Mind and Matter: A Philosophy of Engineering Design, Berlin, Springer. Lewis, D. (1969), Convention: A Philosophical Study, Cambridge (MA), Harvard University Press.

Lopes, D. M. (2007), Shikinen Sengu and the ontology of architecture in Japan, "Journal of Aesthetics and Art Criticism", vol. 65, n. 1, pp. 77-84.

Lowe, E. J. (1998), The Possibility of Metaphysics, Oxford, Clarendon Press. 
Preston, B. (1998), Why is a wing like a spoon? A pluralist theory of function, "Journal of Philosophy", vol. 95, n. 5, pp. 215-254.

Rohrbaugh, G. (2003), Artworks as historical individuals, "The European Journal of Philosophy”, vol. 11, n. 2, pp. 177-205. Searle, J. R. (1995), The Construction of Social Reality, New York, Free Press.

Terrone, E. (2018a), Recensione di Teoria del progetto architettonico. Dai disegni agli effetti, "Rivista di estetica", n. s., 67, pp. 229-234.

Terrone, E. (2018b), (2018) Appearance and history: The autographic/allographic distinction revisited, "British Journal of Aesthetics”, 58, 1, pp. 71-87.

Varzi, A. C. (2011), On doing ontology without metaphysics, “Philosophical Perspectives”, vol. 25, pp. 407-423.

Wittgenstein, L. (1953), Philosophical Investigations, Oxford, Blackwell. 